\title{
HUMANITIES
}

Creative WORKS

\section{"You have to try"}

Previously published at www.cmaj.ca

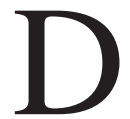
on was 82 when he died. Over the years, he pushed for new information about chronic obstructive pulmonary disease and yet was resistant to suggested treatments beyond his conventional inhalers if he didn't think he was ready. He politely turned down theophyllines, supportive home care, anxiolytics for his tendency to panic and had even turned away the oxygen vendors when they came to set up an oxygen concentrator the day before his final hospital admission. He was never ready for death; 24 hours before he died he told me, "We will get through this." And then he added, "What other option is there?"

He was always elegantly dressed for clinic visits, with a spring in his step and an old-world politeness that made each interaction a pleasure. He worked out in his own home gym until his last months and was still using dumbbells in his hospital chair during his final admission; this was a source of pride for him when he had lost so many.

During this last admission low-dose morphine worked well for his dyspnea and related anxiety. ${ }^{1}$ Nebulized furosemide looked like a breakthrough until a well-conducted " $n=1$ " randomized controlled trial proved otherwise. ${ }^{2}$ His disappointment (and mine) was palpable. Feeling powerless to do much more than visit and spend some time with him, I tried to fathom why there were days when he struggled to reach the bathroom and others when he could do two laps of the medical teaching unit. Nothing seemed to explain the fluctuation other than whether or not from his viewpoint he was getting encouragement from those around him. One thing was certain: dying and death were shadows he chose to ignore.

His worst day was when he believed he was headed for a nursing home, a

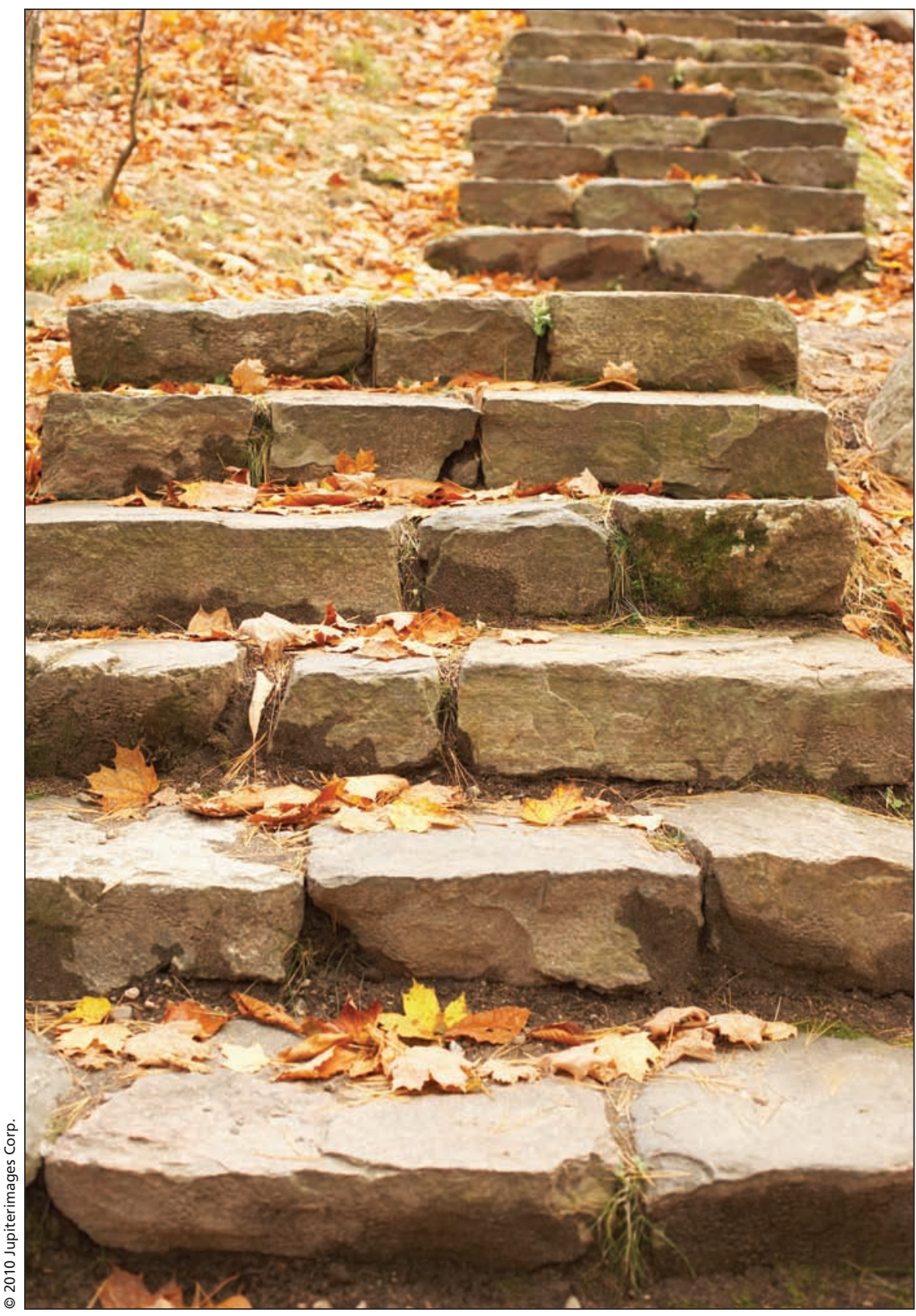

plan he interpreted as a fait accompli after overhearing a discussion on rounds. "They might as well have taken out a gun and shot me," he said later.

Not far behind was the day when a junior resident stopped by to establish
Don's code status, a modern practice where the documented decision seems the priority, rather than the person to whom the decision relates. Don's reluctance to engage in discussion was interpreted as an indication that he 
desired no extraordinary interventions. Those who knew him better recognized Don's reluctance as a symptom of his inability to contemplate, let alone discuss, his own mortality, or the option of delegating decisions about end-of-life care to his already frail wife. Yet, a total stranger, relatively new to the profession, recorded a no code decision for this man who worked out in a gym at home, who was never previously on oxygen and had never required any emergency room visits until just prior to this - only his second admission - let alone any form of assisted ventilation. Don was still angry the next day and shaking his head he simply said, "Don't send in the 20 year olds to do that."

Don and I revisited the subject the next day. A powerful belief in the value of life was the root of his hope, so I wasn't surprised that we reached a consensus on time-limited trials of noninvasive ventilation and even intubation for anything reversible, because, after all, as he said, "You have to try." $\mathrm{He}$ considered not trying an abandonment of hope and hope was an essential part of Don's worldview. He wasn't about to reject hope or let anyone else sabotage it as long as he literally had breath enough to fight.

Hope-related imagination clearly is an important source of both vulnerability and strength, even in situations of dying and death. ${ }^{3}$ As members of health care teams we come with hopes of our own, whether we are aware of them or not, or whether they align with those of our patients and families. ${ }^{4}$ As a flip side to uncertainty, hope provides a resource for coping by enabling patients to imagine, seek support for, and invest energy in scenarios that add to their quality of life as illness progresses. ${ }^{4}$ Left unexplored, (and seldom do we pay more than lip service to hope in conventional medical practice), discordant hope(s) between clinicians and patients or families can become a source of mismatched goals that can plague the current models of care for chronic obstructive pulmonary disease ${ }^{5}$ and other chronic illnesses. ${ }^{4}$

Hope had Don trying stairs when he hadn't done so in weeks. As the awful specter (for him) of the nursing home faded, renewed hope had him doing laps of the unit again. Getting home was the hope that fueled his resolve. To his credit, and that of his care team, he did get out on a pass for one weekend to enjoy a visit to his beloved Point Pleasant Park and a picnic with his wife.

Each day I visited we would shake hands, and in a gentle role reversal, he would ask me how $I$ was doing. Nevertheless, the sands of time were running away from him. As his frailty increased, goals of care were sensitively re-aligned. Ironically, the end came when I was out of province and just a day after he said to me, "We will get through this."

Don provided some essential practical lessons on hope. What seemed a quiet stubbornness to not face reality on his part had everything to do with his hope - the force that helped him live life his way. Devising care respectful of hope has everything to do with the second goal of medicine, the relief of suffering. Medicine, it seems to me, is ripe for a rebalancing toward care that remembers and restores the human side of the equation. Care that respects hope can help patients like Don to "get through."

\section{Graeme Rocker MD \\ Professor of medicine \\ Dalhousie University \\ QEII Health Sciences Centre \\ Halifax, NS}

Graeme Rocker would like to thank Cathy Simpson MDiv for her outstanding contributions to the care of Don and his family. The family gave permission for Don's story to be told.

\section{REFERENCES}

1. Rocker G, Horton R, Currow D, et al. Palliation of dyspnoea in advanced COPD: revisiting a role for opioids. Thorax 2009;64:910-5.

2. Guyatt G, Sackett D, Adachi J, et al. A clinician's guide for conducting randomized trials in individual patients. CMAJ 1988;139:497-503.

3. Simpson C. When hope makes us vulnerable: a discussion of patient-healthcare provider interactions in the context of hope. Bioethics 2004;18:428-47.

4. Davison SN, Simpson C. Hope and advance care planning in patients with end stage renal disease: qualitative interview study. BMJ 2006;333:886.

5. Simpson AC, Rocker GM. Advanced chronic obstructive pulmonary disease: rethinking models of care. QJM 2008;101:697-704.

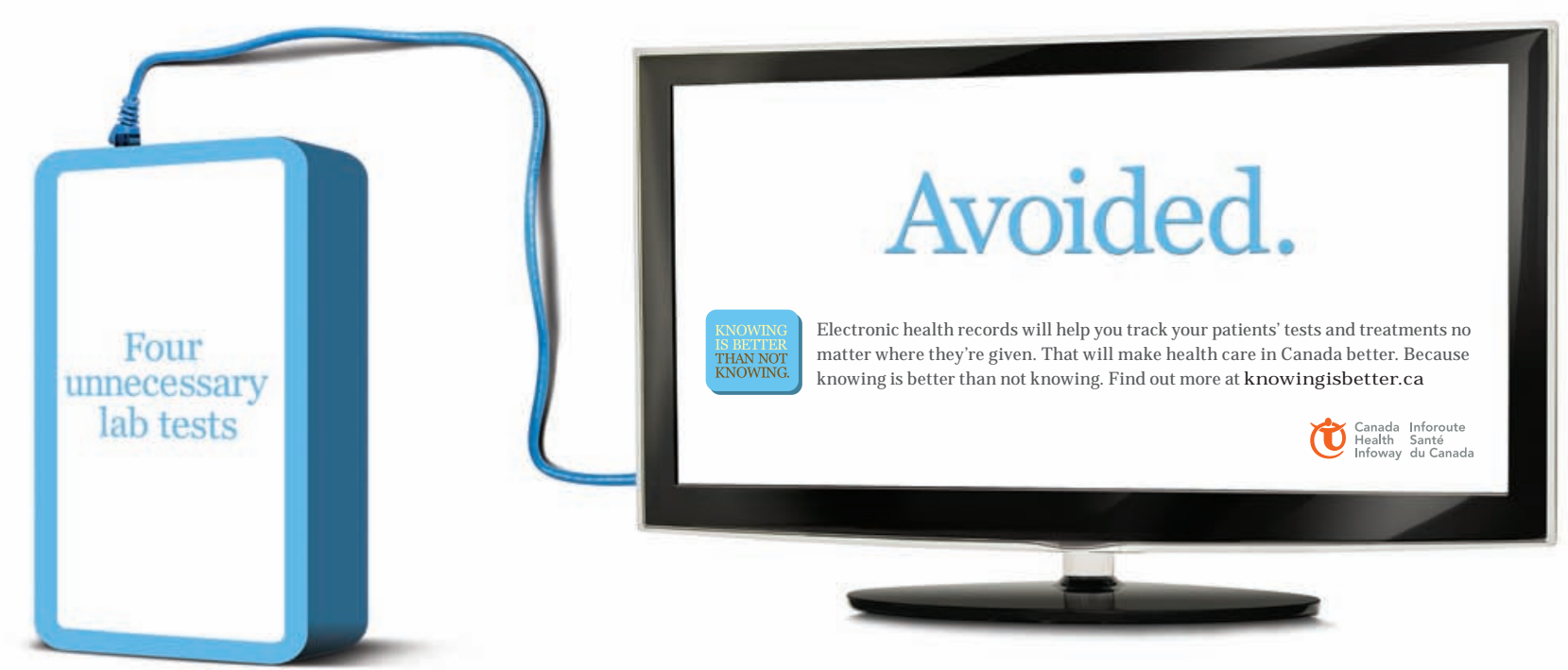

